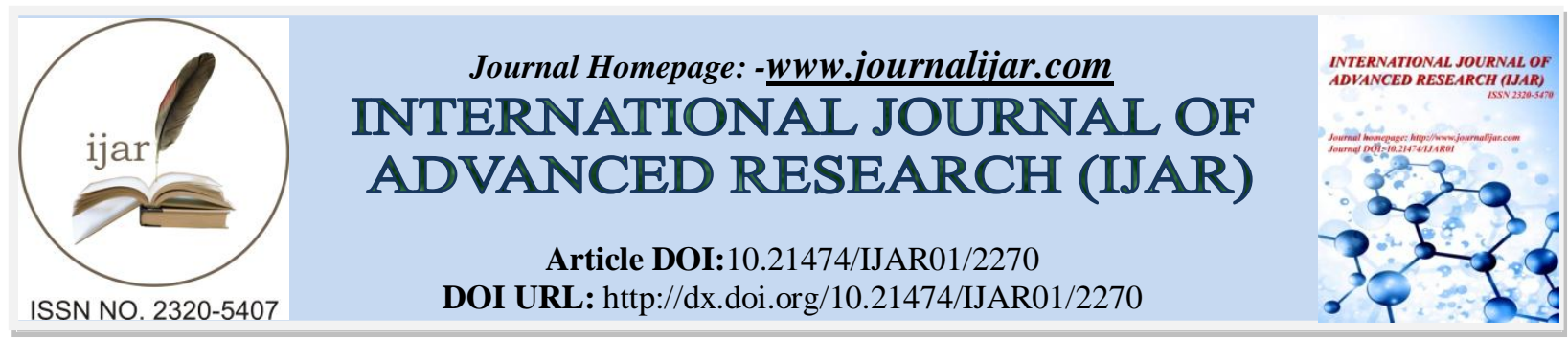

RESEARCH ARTICLE

\title{
KINESIO TAPING FOR UPPER LIMB FUNCTION IN CHILDREN WITH HEMIPLEGIC CEREBRAL PALSY.
}

Nanees E. Mohamed, PhD*.

Department of Physical Therapy for Disturbance of Growth and Development in Children and its Surgery, Faculty of Physical Therapy, Cairo University, Egypt.

\section{Manuscript Info}

Manuscript History

Received: 29 September 2016

Final Accepted: 30 October 2016

Published: November 2016

Key words:-

Hemiplegic cerebral palsy;

Pediatric;Kinesio Taping;Upper

extremities.

\section{Abstract}

Background: Children with hemiplegia were unable to use their hand effectively in daily activities. Improvement of their upper limb functionis anobjective of most therapeutic approaches.

Objective:The purpose of this study was to determine the effect of kinesio taping on upper limb function in hemiplegic children.

Patients and Methods:Fortyhemiplegic children from both sexes participated in this study, their ages ranged from two to four years. They were divided randomly into two groups: control and study. Control group received a designed physical therapy program with emphasis on hand function training, while study group participated in the same program in addition to kinesio taping. The wrist range of motion assessed using the digital goniometer andfine motor skills evaluated by using Peabody developmental motor scale for children of both groups before and after three successive months of treatment.

Results:There wasa significant increase in the wrist range of motion in favor to study group. Also, there was a statistically significant improve in grasping and visual motor integration in favor to study group.

Conclusion:The obtained resultssupport theintroduction ofkinesio taping with physical therapy program for hemiplegic children that improve range of motion, and functional activities.

Copy Right, IJAR, 2016,. All rights reserved.

\section{Introduction:-}

Hemiplegia is a type of spastic cerebral palsy $(\mathrm{CP})$ with unilateral involvement of upper and lower extremities opposite to the side of cerebral injury. The upper limb is usually more severely involved than lower one (Dulac et al., 2013).The resulting impairments to upper extremities may include abnormal muscle tone with imbalance between agonist and antagonist muscles that affects the posture of the upper extremity (Armer et al., 2008). The extent of impaired movements demonstrates shoulder internal rotation, elbow flexion, forearm pronation, wrist and finger flexion and thumb adduction and/or flexion in addition to reduced strength, as well as tactile and proprioceptive disturbances (Koman et al., 2008; Shepherd et al., 2011).These limit hand functions, interfering with play, exploration, self-care and other daily life activities (Jasperset al., 2009).Secondary contractures and joint deformities reduce the range of motion. Wrist flexion movement is more dominant in relation to the increased degree of flexion causing extension of this joint to be difficult (Vaz et al., 2006).

Corresponding Author:-Nanees E. Mohamed, PhD.

Address:-Department of Physical Therapy for Disturbance of Growth and Development in Children and its Surgery,

Faculty of Physical Therapy, Cairo University, Egypt. 
The proximal and distal instability, as well as, muscle weakness, sensory problems, spasticity, and soft tissue tightness may interfere with hemiplegic child ability for reaching, grasping, and object manipulation with proper visual motor integration(Dulac et al., 2013).Poor upper extremity positioning may result in insufficient movement and postural misalignment. Kinesio taping can be applied to realign the upper extremity in more optimal alignment for movement. Yasukawa et al. (2006) found that application of kinesio tape help hand function including reaching, grasping and release, and object manipulation. So the aim of the current study was to detect the effect of Kinesio taping on changing the quality of the affected upper extremity performance in children with hemiplegic cerebral palsy.

\section{Subjects and Methods:- Study Design:-}

This study is a randomized-control study that was conducted during the period from November 2015 to April 2016 after approving this study by the research ethical committee of Faculty of Physical Therapy, Cairo University. The treatment program performed in Faculty of Physical Therapy outpatient clinic, Cairo University, Egypt.

\section{Subjects:-}

FortyhemiplegicCP children of both sexes with ages ranged from two to four years selected from the outpatient clinic, Faculty of Physical Therapy, Cairo University.

Subjects included if they had mild degree of spasticity of upper extremityandno fixed deformity of both upper extremities.Also, they have normal visual and auditory functions and able to follow the instructions. Subjects were excluded ifthey had hyper-sensitivity to the tape,moderate and severe spasticity or history of surgical interferenceat the upper extremities.

To avoid bias, children' random assignments performed through two stages: firstly, colleague physical therapists who were working in the outpatient clinics of the Faculty of Physical Therapy, Cairo University, reported all patients who fulfilled the inclusion criteria of the study. Secondly, after sufficiently informing all subject's parents about the study protocol and the objective of the study and signing an informed consent form prior to their voluntary participation in the study, subjects who met the inclusion criteria assigned randomly and equally to one of two groups: control group, which received a designed physical therapy program with emphasis on hand function training; or study group, which received the same therapy program in addition to kinesio taping. The randomization was done by opening an opaque envelope prepared by an independent individual with random number generation.Figure 1 shows the recruitment process and the flow chart of participants throughout the study.

\section{Instrumentation:- \\ For Evaluation:- \\ Peabody developmental motor scale (PDMS-2):-}

This test is standardized and normed for children aged from birth to five years and has been validated for use as a discriminative measure. It is responsive to change in the CP population for both infants and toddlers (Wang et al., 2006).VanHartingsveldt et al. (2005) conclude that PDMS-2 has large test-retest and inter-rater reliability, the coefficients varied from $r=0.84$ to 0.99 .

The PDMS-2 is composed of six subtests; reflexes, stationary, locomotion, object manipulation, grasping and visual motor integration (Folio and Fewell, 2000).Results from its subtests are used to generate the three composite scores: Gross Motor Quotient (GMQ), Fine Motor Quotient (FMQ), and Total Motor Quotient (TMQ). Scores are presented as percentiles, standard scores, and age equivalents (Folio and Fewell, 2000).In this study, the primary outcome measure was grasping and visual motor integration. For each domain a standard score is calculated.

\section{Digital Goniometer:-}

The range of wrist extension measured using the Digital Absolute + Axis (AA) ${ }^{\text {TM }}$ Goniometer(Fabrication Enterprises Inc. P.O. Box 1500. White Plains, NY 10602 (USA)). It can measure any joint angle or range of motion quickly and accurately.It is composed of the integral absolute vertical and horizontal levels are permanently incorporated into the digital goniometer arm, goniometer reads $0-185^{\circ}$ degrees on LCD screen, has ability to freeze angle measurement, goniometer exterior is powder-coated steel with inch/cm marks screened onto arms, Powered by $19 \mathrm{~V}$ battery. 


\section{For Treatment:-}

Physical therapy tools:-

Physical therapy tools that were used for conducting physical therapy program included mat, medical balls, rolls, wedges, sitting chair, balance board, and standing bar.Different sizes and shapes of occupational therapy tools including balls, cubes, cards, dough, marbles, scissors, puzzle, keys, zipper, beads, tooth brush and paste, buttons, jar, lock and key were used in the treatment of both groups.

\section{KinesioTaping:-}

Elastic kinesiotaping was used in study group for three successive months. The materials used for application of taping include; An organic solvent:alcohol pads to clean the area before kinesio application, A scissor:to cut the kinesiotape, and Elastic (Kinesio Tex® Tape) $5.0 \mathrm{~cm}$ width X 5m length (2.0 in X $16.4 \mathrm{ft}$ ).

\section{Procedure:-}

\section{Evaluative Procedure:-}

\section{Assessment for eligibility of subjects:-}

Physical examination was done to select subjects according to inclusion criteria.

The assessment conducted for each child of both groups individually before and after three successive months of treatment. The protocol of the work explained to children before conducting this study. Each child was asked to perform two test trials before specific tests to be familiar with the instrument.

\section{Peabody developmental motor scale (PDMS-2):-}

The child was seated in comfortable position. The examiner was seated side by side to the child or opposing him/her. Evaluation of the hand function as grasping and visual motor integration subtests of the PDMS-2 is based on scoring each item as 2, 1, and 0 . After administration of all tests in both subtests, raw and standard scores calculated.

Assessment of fine motor skills of grasping section in PDMS-2 included administration of 26 subtests that measure child's ability to use his/her hands. It begins with the ability to hold an object with one hand and progresses up to actions involving the controlled use of the fingers of both hands. While, assessment of fine motor skills of visual motor integration section in PDMS-2 included administration of 72 subtests that measure child's ability to use his/her visual perceptual skills to perform complex eye-hand coordination tasks such as reaching and grasping for an object, building with blocks, and copying designs. Application of the scale included detecting entry point (in which $75 \%$ of children in the normative sample at that age passed), basal level (the last score of 2 on three items in a row before the 1 or 0 scores) and ceiling level (when the child scores 0 on each of three items in a row) for each child before and after treatment application. This scale is based on scoring each item as follows; 2: The child performs the item according to the criteria specific for mastery. 1: The child performance shows a clear resemblance to the item mastery criteria but does not fully meet the criteria. 0: The child cannot or will attempt the item, or the attempt does not show that skill is emerging.

\section{Digital Goniometer:-}

To start the evaluation process, the child was sitting on a chair with knee, and hip were $90^{\circ}$ flexed, the forearm rested on atable beside the tested side with shoulder adducted beside the body and elbow $90^{\circ}$ flexed. The ulnar styloid process was used as a fulcrum for measuring the wristextension range of motion. Then the child was asked to extend his/her wrist. The measurement angle was recorded in LCD screen. The procedure repeated three times (with a rest period in between) and the average was taken.

\section{Treatment Procedures:-}

\section{Physical therapy program:-}

Children of both groups received the designed physical therapy exercise program with emphasis on hand function. For both groups treatment applied one and half hours three times weekly for three successive months.

Physical therapy exercises program includedapproximation,range of motion exercises for wrist joint,strengthening exercisesfor the wrist extensors, hand weight bearing exercises,facilitation of dynamic standing, stoops and recover from standing position, balance training exercises, gait training exercises, ascending and descending stairs, and gentle passive stretching exercises as well as exercises to facilitate hand function (reaching, grasping, carrying and release and bilateral hand use). 


\section{Kinesiotaping:-}

Before therapeutic taping conducted, skin sensitivity test was done by applying a square piece of kinesiotape ( 5 x 5 $\mathrm{cm})$ over the back and kept for 48 hours, then removed and the skin observed for a reaction to the tape. Since no reaction detected, the tape applied to study group for three days, then removed for 24 hours to allow skin perspiration and then reapplied again.During application of the tape, each child in the study group received the designed physical therapy program. Repetition of tape application and removal was for a period of three months(Elkhatib et al., 2012; Kase et al., 2003).

For applying of Taping (Kinesio Tex ${ }^{\circledR}$ Tape of $5 \mathrm{~cm}$ width) the skin over the applied area of tapping cleaned before application of tape by organic solvent (Alcohol pads) (Kumbrink, 2012). Then, one Y strap prepared for each child individually. The length of the tape from the wrist, wrapping around the forearm, to the triceps, across the spine of the scapula to the spine was measured (Kase et al., 2006).

One end of the tape anchored on the dorsum hand of the affected limb proximal to metacarpophalangeal joint with no tension. With the wrist is in maximum extension the second anchor placed on the distal third of the forearm with no tension. Thenthe wrist was flexed while holding the anchors to stabilize the tape and the tape was gently rubbed proximal to distal.This provided tape tension and some degree of maintained wrist extension(Kase et al., 2006).

Then the tapewrapped around the forearm with paper-off tension, as the forearm gradually supinated. While, with slight flexion of the elbow the tape continued along the triceps. Then from horizontal adduction position the superior tail applied along the spine of the scapula. Also, from shoulder flexion position the posterior tail applied along the lateral side of rib cage toward its scapular origin(Kase et al., 2006).

Finally, instructions were given foreach child to avoid vigorous activities for 20 minutes after tape application which is required for the glue to become fully activated(Hewston et al., 2010).Also, direct friction forces to the edges of the tape should be avoided.

\section{Statistical Analysis:-}

All statistical measures were performed using the Statistical Package for Social science (SPSS) program version 18 for windows. Descriptive statistics and t-test was used for comparing the mean general characteristics. "MannWhitney test" was conducted to compare difference between groups in grasping and visual motor integration. "Wilcoxon test" was used to compare between "pre" and "post" treatments for grasping and visual motor integration for each group."Paired t test" was used to compare between "pre" and "post" test for range of motion for each group. "Unpaired t test" was conducted to compare range of motion between both groups. Statistical tests were considered significant if $(\mathrm{p}<0.05)$.

\section{Results:-}

Baseline characteristics of the subjects are shown in Table 1. No statistically significant differences existed between groups recording age, height, and weight.

The results of this study showed no significant differences $(\mathrm{P}>0.05)$ in the pre-treatment values in all measured variables in both groups (tables 2,3,4). Significant improvement was observed in both grasping and visual motor integration domains when comparing the pre- and post-treatment values in both control and study groups as presented in tables $(2,3)$.Also, there was a significant increase in the wrist range of motion in both control and study groups when comparing their pre- and post-treatment mean values as revealed from table (4).

Significant improvement was also observed when comparing the post-treatment mean values of the grasping, visual motor integration and range of motion between the two groups in favor of the study group $(\mathrm{P}<0.05)$ as shown in Table 2, 3 and 4 . 
Table 1:-General characteristics of participants

\begin{tabular}{|c|c|c|c|c|c|}
\hline & \multicolumn{2}{|c|}{ Mean \pm SD } & \multirow[t]{2}{*}{$t$-value } & \multirow[t]{2}{*}{$P$-value } & \multirow[b]{2}{*}{ Significance } \\
\hline & Control group $(n=20)$ & Study group $(n=20)$ & & & \\
\hline Age (Month) & $34.00 \pm 6.06$ & $35.35 \pm 7.40$ & 0.630 & 0.53 & NS \\
\hline Weight (kg) & $13.75 \pm 1.29$ & $13.70 \pm 1.30$ & 0.122 & 0.90 & NS \\
\hline Height $(\mathrm{cm})$ & $79.40 \pm 4.80$ & $79.00 \pm 3.89$ & 0.289 & 0.77 & NS \\
\hline
\end{tabular}

SD, standard deviation; $t$-value, unpaired $t$-value; $P$-value, probability value; NS, non-significance.

Table 2:- Comparing the median (IQR) of the grasping pre and post treatment within and between both groups.

\begin{tabular}{|c|c|c|c|c|}
\hline & \multicolumn{2}{|c|}{ Median (IQR) } & \multirow{2}{*}{$P$-value } & \\
\cline { 2 - 4 } & Control group $(n=20)$ & Study group $(n=20)$ & & 0.471 \\
\hline Pretreatment & $1(1,2)$ & $1(1,1)$ & -0.721 & $0.001^{*}$ \\
\hline Post-treatment & $2(2,2)$ & $3(3,3)$ & & \\
\hline$Z$-value & -3.162 & -3.716 & & \\
\hline$P$-value & $0.002 *$ & $0.001 *$ & & \\
\hline
\end{tabular}

IQR, inter quartile range; $P$-value, probability value. * Significant level is set at alpha level $<0.05$.

Table 3:- Comparing the median (IQR) of the visual motor integration pre and post treatment within and between both groups.

\begin{tabular}{|c|c|c|c|c|}
\hline & \multicolumn{2}{|c|}{ Median (IQR) } & \multirow{2}{*}{$Z$-value } & \multirow{2}{*}{$P$-value } \\
\cline { 2 - 4 } & Control group $(n=20)$ & Study group $(n=20)$ & & 0.708 \\
\hline Pretreatment & $1(1,1.75)$ & $1(1,1)$ & -4.349 & $0.001^{*}$ \\
\hline Post-treatment & $2(1,2)$ & $3(3,3)$ & & \\
\hline$Z$-value & -3.00 & -3.716 & & \\
\hline$P$-value & $0.003^{*}$ & $0.001^{*}$ & & \\
\hline
\end{tabular}

IQR, inter quartile range; $P$-value, probability value. $*$ Significant level is set at alpha level $<0.05$.

Table 4:- Comparing the mean values of the wrist range of motion (degree) pre and post treatment within and between both groups.

\begin{tabular}{|c|c|c|c|c|}
\hline \multirow{2}{*}{} & \multicolumn{2}{|c|}{ Means \pm SD } & \multirow{2}{*}{$t$-value } & \multirow{2}{*}{$P$-value } \\
\cline { 2 - 4 } & Control group $(n=20)$ & Study group $(n=20)$ & & 0.866 \\
\hline Pretreatment & $7.75 \pm 0.96$ & $7.80 \pm 0.89$ & -0.170 & $0.001^{*}$ \\
\hline Post-treatment & $10.35 \pm 1.03$ & $16.80 \pm 1.39$ & & \\
\hline t-value & -11.113 & -24.329 & & \\
\hline$P$-value & $0.001^{*}$ & $0.001^{*}$ & & \\
\hline
\end{tabular}

SD, standard deviation; $t$-value, unpaired $t$-value; $P$-value, probability value. ${ }^{*}$ Significant level is set at alpha level $<0.05$. 


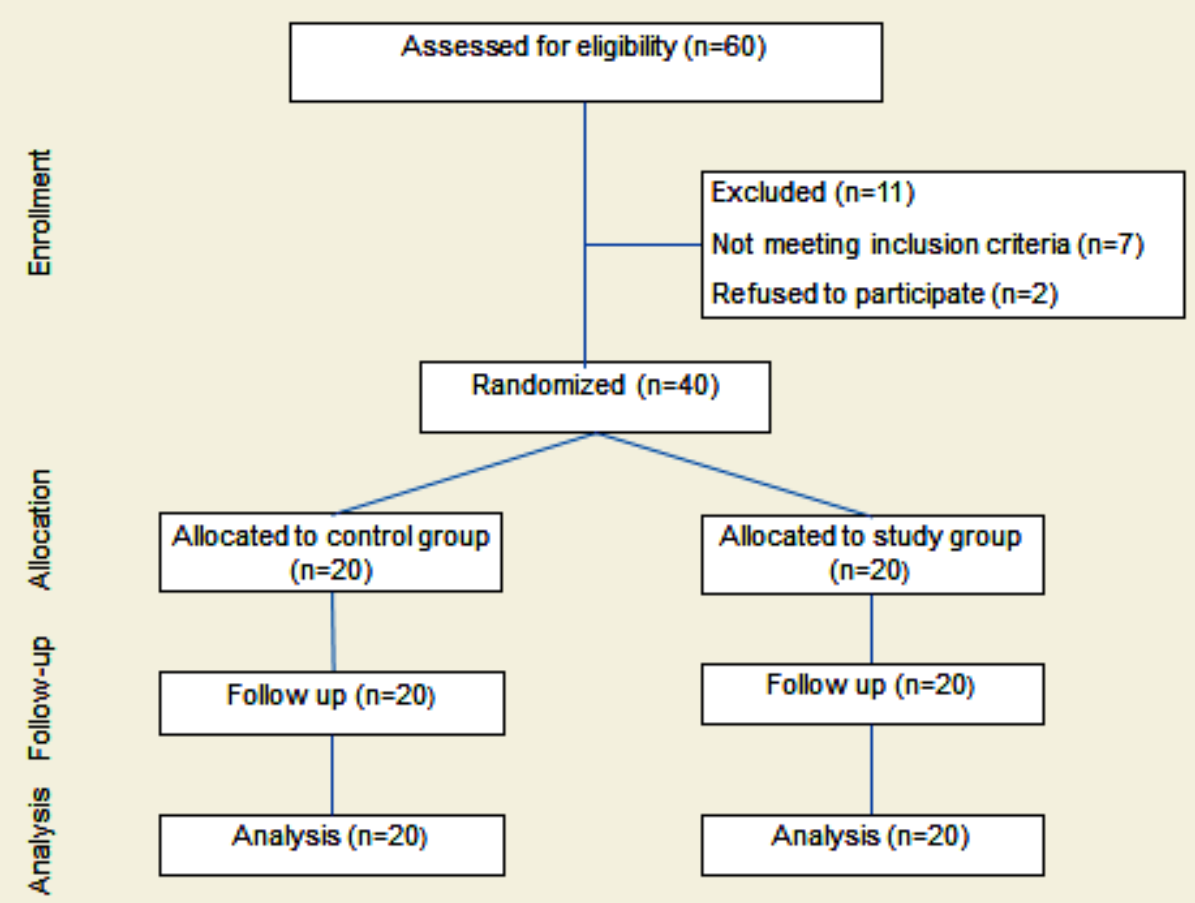

Figure 1:- Consort diagram showing the flow of the study participants through each stage of the randomized trial.

\section{Discussion:-}

In hemiplegic cerebral palsy skilled hand movements are typically impaired (Mackenzie et al., 2009), and there is weakness in the wrist, forearm, and elbow extension (Lennons and Ashburn, 2001). Almost 50\% of children with CP present an arm hand dysfunction (Arnould et al., 2007; Fedrizzietal., 2004).Hand function problems of hemiplegic CP children usuallyaccompaniedby problems of motor control, sensibility and sensory processing,as well as persistence of primitive grasp reflex(Bax et al., 2006).Children with hemiplegia seldom use their paretic hand spontaneously in daily activities; (Fedrizziet al., 2004; Pagliano et al., 2001).Increasing attention focused on upper limb function in children with CP. So, the current study was conducted to detect the effect of the application of kinesio taping for affected upper extremity on changing its fine motor performance and wrist extension range of motion in hemiplegic children.

Pre-treatment findings revealed that both groups of children have limited wrist active extension range of motion this might attribute to the fact that in hemiplegic children the flexor carpi ulnaris muscle is two times more active as compared to healthy peers. It causes movement disorders and mal-posture of the hand with limited wrist extension (Friden and Lieber, 2003).Also, inappropriate fine-motor function both grasping and visual motor integration observed. In hemiplegic children, there are spasticity, co-activation of agonist antagonist muscles, muscle weakness, and limited range of motion, all of which affect gross- and fine-motor function (Chen and Yang, 2007).

The physical therapy program provides a challenge to stimulate the sensorimotor system toward regaining normal voluntary movement and upper extremity functional use. Regaining functional use of the upper extremity is one of the most challenging tasks for both the patient and the therapist. Its result has an impact on the child's physical, psychological, and emotional well-being. The improvement observed in both groups may be attributed to the physical therapy program that emphasis on hand function exercises. This was consistent with Azzam (2012) findings. He concluded that hand function training improves functional abilities of the hand in hemiplegic CP children.

The kinesio ${ }^{\circledR}$ taping has numerous advantages over the functional system of the body. It could improve strength, functional activities, proprioception control, and positioning. The Kinesio taping method gives the subject the opportunity to actually give support while maintaining the full range of motion, enabling the individual to participate in physical activity with functional assistance (Grisham and Deming, 2011; Miller and Osmotherly, 2006). 
Post-treatment results showed an upper limb function improvement in the study group when the taping application used. Improvement in the Peabody scores of the grasping and visual motor integration sections as there is a breakdown of the pathological motor schemes and acquisition of more corrected, allowing the emergence of proper movements (Mazzone et al., 2011).Kinesio Taping could stimulate cutaneous mechanoreceptors and thus improve proprioceptive inputs for muscles to perform task-specific functions. These positive effects of mechanoreceptors could cause improvement in fine motor performance.

Normal upper limb functions depend on the ability to statically and dynamically position the limb in an optimal coordinated pattern (Morrissey, 2000). The applied taping technique positioned the upper extremity in the more optimal alignment for movement. Assist the child linking groups of muscles with some proprioceptive influence and cutaneous stimulation which enhances the center nervous system abilities to organize different sensory input to improve the motor output, and improves the child awareness to maintain his/her limb in proper position, that means effective postural control and good body alignment for effective upper limb function. Loh et al.(2010) noticed that for initiating grasping coordination of both external sensory inputs and internal models of the desired movement must exist (Armer et al., 2008).

The effective use of the hand is dependent on a complex interaction of fine motor skills and visual perception. Yasukawa et al. (2006)investigated the effects of Kinesio taping in acute paediatric rehabilitation settings as assessed with the Upper Limb Assessment before and just after taping and after three days of wearing the tape. They showed that Kinesio taping enabled goal-directed movement, increased stability of the shoulder and hand, and supported alignment during reaching and grasping.

In a case study, Camerota et al. (2014) assessed a 17-year-old female with left hemiplegia with 3D motion analysis before and after the neuromuscular taping. Their results have proved that Kinesio Taping recruited upper limb function, especially the preparation of motion and returning phases.

This contradicts the findings of Kara et al. (2015) as they reported no significant difference after tape application regarding fine motor functions according to Bruininks-Oseretsky Test of Motor Proficiency. They believe that the primary reason for non-improvement as children with hemiplegia have to use their non-dominant hand for fine motor tasks if their dominant side is affected.

The range of motion is an important component of body structure and function (Speth et al., 2005).Improvement in active wrist extension range of motion in study group may be as a result of the application of taping. In particular, the treatment drove the movements inside a more functional range of motion. Taping for the dorsum of wrist and forearm could lead to increased firing of cutaneous afferents on the underlying skin. The sensory system gives preliminary information about limb positions and muscle forces to the central nervous system for monitoring and controlling limb movements, planning actions, and providing fluent movement(McGlone and Reilly, 2010).

Mazzone et al.(2011) explored the effects of functional taping on the upper extremity of children with $\mathrm{CP}$ and assessed motor performance using the Upper Limb Assessment. They reported a significant improvement in the 5month period of functional taping. They indicated that functional taping could allow a more functional range of motion, and improve selective finger movements and fine motor manipulation.

The changing in measuring variables of study group might be related to increased sensory awareness from tape application as taping stimulate underlying sensory receptors via surface contact or stretch of the skin that alters the sensory input to the central nervous system and subsequently influences its perception and execution of movement(Blanch et al., 2008). Clinically, the results of this study could help in enhancing the rehabilitation programme for children with hemiplegia.

\section{Conclusion:-}

In conclusion, this study suggests that adding kinesio taping acting as an extra hand to physical therapy program may have significant improvements in the upper limb function of hemiplegic children.

\section{Funding resources:-}

None. 


\section{Conflict of interest:-}

The author declares no conflict of interest.

There is no financial and personal relationship with otherpeople or organization that could inappropriately influencethis work.

\section{Acknowledgement:-}

The author wishes to thank colleagues and all the children and their parents who participated in this study.

\section{References:-}

1. Armer, M., Eliasson, A., Nicklasson, S., Sommerstein, K. and Hagglund, G. (2008): Hand function in cerebral palsy. Report of 367children in a population-based longitudinal health care program. J. Hand Surg. Am., 33:1337-47.

2. Arnould, C., Penta, M. and Thonnard, J.L. (2007): Hand impairments and their relationship with manual ability in children with cerebral palsy. J. Rehabil. Med., 39:708-14.

3. Azzam, AM. (2012): Effect of hand function training on improvement of hand grip strength in hemiplegic cerebral palsy children. J. Nov. Physio. Ther., 2:116.

4. Bax, M., Tydeman, C. and Flodmark, O. (2006): Clinical and MRI correlates of cerebral palsy. JAMA., 296:1602-8.

5. Blanch, P., Melinda, F., Andrew, C. and Bill, V. (2008): A physiological and psychological basis for antipronation taping from a critical review of the literature. Sports Medicine: Pediatric Physical Therapy, Therapeutic taping in CP. Lippincott Williams and Wilkins, 38(8): 617-631.

6. Camerota, F., Galli, M., Cimolin, V., et al. (2014): Neuromuscular taping for the upper limb in cerebral palsy: A case study in a patient with hemiplegia. Dev. Neuro. Rehabil., 17: 384-7.

7. Chen, Y. and Yang, T. (2007): Effect of task goals on the reaching patterns of children with cerebral palsy. J. Motor Behavior., 39(4):317-24.

8. Dulac, O., Lassande, M. and Sarnot, H.B. (2013): Handbook of clinical neurology Vol 111 Pediatric Neurology. In: Richards CL and Malouin F. editors. Cerebral palsy: Definition, assessment and rehabilitation. Elsevier.

9. Elkhatib, R.S., El Negmy, E.H. and Salem, A.H. (2012): Kinesio arm taping as prophylaxis against the development of Erb's engram. J. of Adv. Res.,http://dx.doi.org/10.1016/j.jare.2012.08.006.

10. Fabrication Enterprises Inc. P.O. Box 1500. White Plains, NY 10602 (USA). https //WWW.fabent.com/evaluation/range-of-motion-evaluation/

11. Fedrizzi, E., Pagliano, E., Andreucci, E. and Oleari, G. (2003): Hand function in children with hemiplegic cerebral palsy: Prospective follow-up and functional outcome in adolescence. Dev. Med. Child Neurol., 45(2):85-91.

12. Folio, M.R. and Fewell, R.R. (2000): Peabody developmental motor scales examiner's manual. $2^{\text {nd }}$ edition. An international publisher. Austen.

13. Friden, J. and Lieber, R.L. (2003): Spastic muscle cells are shorter and stiffer than normal cells. Muscle Nerve., 27:157-64.

14. Grisham, S.R. and Deming, L.M. (2011P):Pediatric life care planning and case management. 2nd ed. Taylor and Francis group;. pp. 520-1.

15. Hewston, T., Austin, K., Brett, K., et al. (2010): An illustrated guide to taping techniques principles and practice. 2nd ed. pp: 221-70.

16. Jaspers, E., Desloovere, K., Bruyninckx, H., Molenaers, G., Klingels, K. and Feys, H. (2009): Review of quantitative measurements of upper limb movements in hemiplegic cerebral palsy. Gait Posture, 30(4):395-404.

17. Kara, O.K., Uysal, S.A., Turker, D., Karayazgan, S., Gunel, M.K. andBaltaci, G. (2015): The effects of Kinesiotaping on body functions and activity in unilateral spastic cerebral palsy: A single-blind randomized controlled trial. Dev. Med. Child Neurol., 57: 81-88.

18. Kase, K., Wallis, J. and Kase, T. (2003): Clinical therapeutic applications of the Kinesio taping method. 2nd ed. Ken Ikai Co. Ltd., Tokyo, Japan. pp.189-211.

19. Kase, K., Martin, P. and Yasukawa, A. (2006): Kinesio® taping in pediatrics fundamentals and whole body taping infant to adolescent full color step-by-step. 2nd edition.

20. Koman, L.A., Williams, R.M.M., Evans, P.J., Richardson, R., Naughton, M.J., Passmore, L. and Smith, B.P. (2008): Quantification of upper extremity function and range of motion in children with cerebral palsy. Dev. Med. Child. Neurol., 50:910-7. 
21. Kumbrink, B.K. (2012): Taping: an illustrated guide, basic, technique, indication. Springer-Verlag Berlin Heidelberg.

22. Lennons, S. and Ashburn, A. (2001): The bobath concept in stoke rehabilitation. A focus group study of the experienced physiotherapists perspective. Disability Rehab., (22):665-674.

23. Loh,M.N.,Kirsch, L.,Rothwell, J.C., Lemon, R.N. and Davare, M. (2010): Information about the weight of grasped objects from vision and from internal models interacts within the primary motor cortex. J. Neurosci., 19; 30(20): 6984-6990.

24. Mackenzie, S.J., Getchell, N., Modlesky, C.M., Miller, F. and Jaric, S. (2009): Using grasping tasks to evaluate hand force coordination in children with hemiplegic cerebral palsy. Arch. Phys. Med. Rehabil., 90(8): 14391442.

25. Mazzone, S., Serafini, A., Iosa, M., Aliberti, M.N., Gobbetti, T., Paolucci, S. andMorelli, D. (2011):Functional taping applied to upper limb of children with hemiplegic cerebral palsy: A pilot study. Neuropediatrics, 42(6): 249-53.

26. McGlone, F. and Reilly, D. (2010): The cutaneous sensory system. Neurosci. Biobehav. Rev., 34: 148-59.

27. Miller, P. and Osmotherly, P. (2007): Dose scapular taping facilitate recovery for shoulder impingement syndrome? A pilot randomized controlled trail. J. Manual and Manipulative Therapy, 17(1):6-13.

28. Morrissey, D. (2000): Proprioceptive shoulder taping. J. Body Mov. Ther., 4: 189-194.

29. Pagliano, E., Andreucci, E., Bono, R., Semorile, C., Brollo, L. and Fedrizzi, E. (2001): Evolution of upper limb function in children with congenital hemiplegia. Neurol. Sci., 22:371-5.

30. Shepherd, J., Procter, S. and Coley, I. (2011): Self-care and adaptations for independent living. In Case-Smith J, Allen A, Pratt P (eds.), Occupational therapy for children, $4^{\text {th }}$ ed., St. Louis, MO: Mosby.

31. Speth, L.A.W.M., Leffers, P., Janssen-Potten, Y.J.M. and Vles, J.S.H. (2005):Botulinumtoxin A and upper limb functional skills in hemiparetic cerebral palsy: A randomized trial in children receiving intensive therapy. Dev. Med. Child Neurol., 47:468-73.

32. vanHartingsveldt, M.J., Cup, E.H. and Oostendorp, R.A. (2005): Reliability and validity of the fine motor scale of the Peabody Developmental Motor Scales-2. Occup. Ther. Int., 12(1):1-13.

33. Vaz, D.V., Mancini, M.C., Fonseca, S.T., Vieria, D.S.R. and deMeloPertence, A.E. (2006): Muscle stiffness and strength and their relation to hand function in children with hemiplegic cerebral palsy. Dev. Med. Child Neurol., 48:728-33.

34. Wang, H.H., Liao, H.F. and Hsieh, C.L. (2006): Reliability, sensitivity to change, and responsiveness of the Peabody Developmental Motor Scales-second edition for children with cerebral palsy. Phys. Ther., 86:1.

35. Yasukawa, A., Patel, P. and Sisung, C. (2006): Pilot study: Investigating the effects of Kinesio taping in an acute pediatric rehabilitation setting. Am. J. Occup. Ther., 60:104-10. 